\title{
Gehirnentwicklung in der Pubertät
}

\section{Teenagerzeit beeinflusst psychische Krankheiten}

Während der Teenagerzeit finden im menschlichen Gehirn gravierende Veränderungen statt, die auch einen gewichtigen Einfluss darauf haben können, ob der Betreffende in späterer Folge mentale Leiden, wie etwa eine Schizophrenie, entwickelt oder nicht. Zu diesem Ergebnis kommt eine aktuelle Studie an der University of Cambridge, in deren Rahmen die Gehirne von insgesamt 300 Jugendlichen zwischen 14 und 24 Jahren genauer unter die Lupe genommen wurden. Dabei stellte sich heraus, dass sich in der Pubertät vor allem jene Hirnareale verändern, die mit Entscheidungsfindungsprozessen und komplexem Verhalten in Verbindung stehen.

\section{Konsolidierung des Netzwerks}

„Während jene Bereiche des Gehirns, die mit Basisfunktionen des Körpers wie dem Sehen, Hören oder Bewegen assoziiert werden, schon bis zur Zeit der Pubertät voll entwickelt sind, verändern sich die Areale, die mit komplexen Gedankengängen und der Entscheidungsfindung verbunden sind, immer noch weiter", zitiert „BBC News" Kristie Whitaker, Forscherin am Department of Psychiatry der University of Cambridge. Letztere Regionen seien Nervenzentren mit einer Fülle von unterschiedlichen Verbindungen zu anderen Schlüsselbereichen. „In der Pubertät wird dieses Netzwerk aus wichtigen Knotenpunkten neu konsolidiert und gefestigt", erklärt die Forscherin.

Gemeinsam mit ihrem Team hat sie sich auch angeschaut, welche Gene an dieser Konsolidierung der Netzwerkknoten im pubertierenden Gehirn beteiligt sind. Dabei stellte sich heraus, dass es sich um dieselben Erbfaktoren handelt, die auch mit vielen mentalen Krankheiten wie etwa Schizophrenie in Verbindung gebracht werden. „Dieses Ergebnis passt sehr gut zu der Beobachtung, dass viele psychische Störungen während der Pubertät entstehen", so Whitaker. Natürlich seien in diesem Zusammenhang aber auch andere

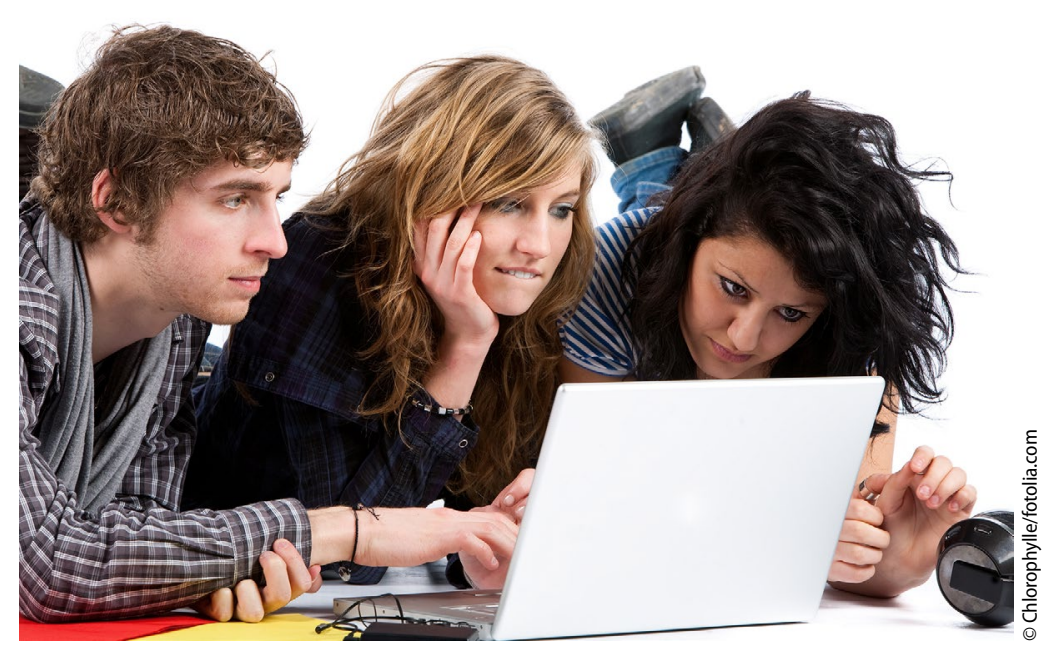

$\Delta$ Junge Menschen in der Pubertät - eine Reise in Richtung Erwachsenwerden

tische Vererbung oder erhöhter Stress in der Kindheit zu beachten, ergänzt die Expertin.

\section{Erwachsen werden}

Den Wissenschaftlern zufolge werfen die jüngsten Untersuchungsergebnisse auch ein interessantes neues Licht auf die bei Teenagern oft vorkommenden raschen Wechsel im Verhalten und der Gemütslage. „Dass sich während dieser Zeit gerade jene Gehirnareale am meisten verändern, die mit Entscheidungsfindungen und komplexem Verhalten in Verbindung stehen, zeigt, dass der Mensch sich in dieser Phase auf einer Reise in Richtung Erwachsenwerden befindet. Das ist ein ungemein wichtiges Entwicklungsstadium, durch das jeder durchmuss, um der denkbar beste und fähigste Erwachsene zu werden", meint Whitaker.

\section{Weitere Informationen}

http://cam.ac.uk

http://psychiatry.cam.ac.uk

Paediatr. Paedolog. Austria 2016 · 51:228 DOI 10.1007/s00608-016-0416-2 Online publiziert: 6. Oktober 2016 (c) Springer-Verlag Wien 2016 